\title{
Breathing Circuit Device
}

National Cancer Institute

\section{Source}

National Cancer Institute. Breathing Circuit Device. NCI Thesaurus. Code C49850.

In an anesthesia machine, the pathway by which a gaseous anesthetic agent and oxygen are delivered to the patient and carbon dioxide is removed. The circuit can be open or closed. 